\title{
TU/e EmonONEN

\section{Deposition of a-Si:H and a-C:H using an expanding thermal arc plasma}

Citation for published version (APA):

Sanden, van de, M. C. M., Severens, R. J., Gielen, J. W. A. M., Paffen, R. M. J., \& Schram, D. C. (1996). Deposition of a-Si:H and a-C:H using an expanding thermal arc plasma. Plasma Sources Science and

Technology, 5(2), 268-274. https://doi.org/10.1088/0963-0252/5/2/022

DOI:

10.1088/0963-0252/5/2/022

Document status and date:

Published: 01/01/1996

Document Version:

Publisher's PDF, also known as Version of Record (includes final page, issue and volume numbers)

Please check the document version of this publication:

- A submitted manuscript is the version of the article upon submission and before peer-review. There can be important differences between the submitted version and the official published version of record. People interested in the research are advised to contact the author for the final version of the publication, or visit the $\mathrm{DOI}$ to the publisher's website.

- The final author version and the galley proof are versions of the publication after peer review.

- The final published version features the final layout of the paper including the volume, issue and page numbers.

Link to publication

\section{General rights}

Copyright and moral rights for the publications made accessible in the public portal are retained by the authors and/or other copyright owners and it is a condition of accessing publications that users recognise and abide by the legal requirements associated with these rights.

- Users may download and print one copy of any publication from the public portal for the purpose of private study or research.

- You may not further distribute the material or use it for any profit-making activity or commercial gain

- You may freely distribute the URL identifying the publication in the public portal.

If the publication is distributed under the terms of Article 25fa of the Dutch Copyright Act, indicated by the "Taverne" license above, please follow below link for the End User Agreement:

www.tue.nl/taverne

Take down policy

If you believe that this document breaches copyright please contact us at:

openaccess@tue.nl

providing details and we will investigate your claim. 


\title{
Deposition of a-Si:H and a-C:H using an expanding thermal arc plasma
}

\author{
M C M van de Sanden, R J Severens, J W A M Gielen, \\ R M J Paffen and D C Schram
}

Department of Applied Physics, Eindhoven University of Technology, PO Box 513, 5600 MB Eindhoven, The Netherlands

Received 11 December 1995, in final form 5 February 1996

\begin{abstract}
This paper deals with the deposition of $\mathrm{a}-\mathrm{C}: \mathrm{H}$ and a-Si:H using the expanding thermal arc technique. The method is compared with other deposition techniques. The basics of the technique are explained and recent results on the deposition of high-quality a-C:H and a-Si:H are discussed. It is shown that high rates, $7 \mathrm{~nm} \mathrm{~s}^{-1}$ for $\mathrm{a}-\mathrm{Si}: \mathrm{H}$ and $50 \mathrm{~nm} \mathrm{~s}^{-1}$ for $\mathrm{a}-\mathrm{C}: \mathrm{H}$, are possible without loss of quality.
\end{abstract}

\section{Introduction}

Plasma deposition of thin amorphous films is still an important industrial activity, because certain properties of thin films cannot be attained using techniques which do not employ plasmas. In a plasma it is possible to generate almost every deposition precursor at relatively modest energy input. This is advantageous because in this way the substrate temperature remains relatively low. Furthermore, material combinations can be tuned by varying the plasma properties. Especially during the last decade, plasma deposition techniques have been improved further, regarding both film quality and deposition rate.

However, it is still a fact that certain large-scale applications of thin amorphous films are hampered by the relatively high production costs. This is not only related to the high cost of plasma-deposited thin films but also to such aspects as substrate costs and packaging. Amorphous silicon (a-Si:H) thin film solar cells may serve as an example of the latter. Still an issue in the production of a-Si:H solar cells is the deposition rate of the intrinsic $\mathrm{a}-\mathrm{Si}: \mathrm{H}$ film. Increasing the deposition rate of $\mathrm{a}-\mathrm{Si}: \mathrm{H}$ at a quality similar to that produced using the classical RF glow discharge could mean a breakthrough in long-term production of our energy needs [1]. Another example concerns the large-scale deposition of corrosion protective amorphous hydrogenated carbon $(\mathrm{a}-\mathrm{C}: \mathrm{H})$ films on steel to replace the environmentally polluting electrogalvanization process [2]. It is evident that the production costs of the plasma-deposited films in this case should be low in order for them to be a realistic alternative. Fast deposition both of $\mathrm{a}-\mathrm{Si}: \mathrm{H}$ and of a-C:H becomes even more interesting if the properties of the deposited films can be improved at larger growth rate; this has been reported for a-Si:H under specific conditions [3].

This paper deals with an approach of fast deposition of a-Si:H and a-C:H using an expanding thermal plasma.
In the next section we will compare this approach with other high-plasma-density sources. Different properties such as electron density and temperature, the ionization and dissociation mechanisms of the injected precursor gas and the influence of transport processes on these mechanism will be dealt with. Finally, recent results of the expanding thermal plasma deposition of a-Si:H and a-C:H will be presented.

\section{Deposition methods}

In plasma deposition several sub-processes can be distinguished. First the plasma is generated either directly in the precursor gas or in a carrier gas. The electrons, or as we will later see, the ions, dissociate and ionize the precursor molecules, thus producing radical fragments and ions. They diffuse or flow towards the substrate, where they may be either chemisorbed or physisorbed, and contribute to film growth. Several surface processes may occur in the adsorbed film on top of the growing film and various advanced in situ techniques have been developed to monitor these different processes [4-7]. They comprise reflection, adsorption, abstraction and desorption of the radicals and of stable molecules such as $\mathrm{H}_{2}, \mathrm{CH}_{4}$ and $\mathrm{SiH}_{4}[8,9]$. These reflected, abstracted and desorbed radicals and stable molecules re-enter the plasma again, thereby contributing to the complicated plasma chemistry. Hence, to describe and to understand the deposition process we need to consider the chemical kinetics of the plasma and the dynamics including re-circulation flows and surface processes $[10,11]$. The uncertainties in the rate coefficients and in the plasma surface interaction make further development of models and experimental verification necessary. As mentioned, the perspective is, however, rewarding, because a better understanding of the deposition process could lead to an increase in deposition rate while maintaining or even improving the quality. 
The first widely applied plasma is the capacitively coupled RF plasma source $[10,12,13]$. In this type of plasma the excitation occurs usually at $13.56 \mathrm{MHz}$, which is applied to one of the electrodes. Typical plasma densities of the order of $10^{16} \mathrm{~m}^{-3}$ are obtained and the operating pressure is in the 10-100 $\mathrm{Pa}$ range. In these plasmas dissociation, ionization and excitation are dominated by electron kinetics as illustrated for example in a $\mathrm{SiH}_{4}$ plasma

$$
\begin{gathered}
\mathrm{SiH}_{4}+\mathrm{e} \rightarrow \mathrm{SiH}_{3}^{+}+\mathrm{H}+2 \mathrm{e} \\
\mathrm{SiH}_{4}+\mathrm{e} \rightarrow \mathrm{SiH}_{3}+\mathrm{H}+\mathrm{e} .
\end{gathered}
$$

Typical rates for both processes are of the order of $10^{-15}$ $10^{-16} \mathrm{~m}^{3} \mathrm{~s}^{-1}$ for electron temperatures in the range of $3 \mathrm{eV}$. It should be mentioned, however, that the electron distribution is strongly non-Maxwellian which means that the temperature indicated refers to an average of the bulk of the distribution. At the indicated values for the electron density and temperature and a typical neutral particle density of $10^{21}-10^{22} \mathrm{~m}^{-3}$ ion fluxes of $10^{19} \mathrm{~m}^{-2} \mathrm{~s}^{-1}$ are produced and somewhat higher fluxes of radicals (dissociation degrees of $10^{-4}-10^{-3}$ are typical for $\mathrm{SiH}_{4}$ plasmas). It should be noted that stable molecule production at the surface is an important loss process of radicals $[10,11]$. These net radical fluxes lead typically to deposition rates of $0.1-1 \mathrm{~nm} \mathrm{~s}^{-1}$. Ions are accelerated in the self-induced bias towards the substrate with energies in the $30-300 \mathrm{eV}$ range, depending on plasma conditions. A complication is the negative ion production, for example

$$
\mathrm{SiH}_{4}+\mathrm{e} \rightarrow \mathrm{SiH}_{2}^{-}+\mathrm{H}_{2}
$$

which eventually leads to particulate growth as negative ions are confined within the glow region of the discharge. Here we will not deal with these complications and we refer to the relevant literature [14]. Another important route of radical generation is by means of secondary reactions of the formed radicals, for example

$$
\mathrm{SiH}_{4}+\mathrm{H} \rightarrow \mathrm{SiH}_{3}+\mathrm{H}_{2} \text {. }
$$

Advantages of the RF capacitively coupled discharge are the large availability, the easy operation and the demonstrated production of high-quality material both for a-Si:H and for a-C:H deposited homogeneously over large areas $\left(>100 \mathrm{~cm}^{2}\right)$. Disadvantages are the usually large ion energy which leads to surface damage, the low growth rate, particulate production at high power and the impossibility of controlling the plasma parameters (such as electron density, radical density and ion energy) independently. The latter is a consequence of the fact that the plasma is active, namely in the ionizing state, which imposes constraints on the operating pressure, dimensions, power density and thus radical and ion fluxes. The relative success of this type of discharge should therefore be put in perspective and one must conclude that this success is more historically determined than based on a proper comparison between the different plasma sources presently available.

As a consequence of the disadvantages of the RF capacitively coupled plasma mentioned and the urge to increase the growth rate while maintaining quality, several high-density plasma sources were developed during the past decade. Among these are the electron cyclotron resonance plasma source [15], the helicon wave-induced plasma source [16], the RF inductively coupled plasma source [17] and the microwave-induced plasma source [18]. An important difference with the RF capacitively coupled plasma is the fact that these types of plasmas are remote; that is, the plasma production is upstream and the treatment is downstream. In this way a geometrical separation is obtained and the different plasma parameters can be influenced independently. Yet they are still active and the active region is an integral part of the plasma source. The region adjacent to the treatment area is passive and some of the constraints on the plasma are eliminated. Precursors for growth are seeded in the flow and are dissociated and ionized by electron impact initially. Secondary reactions with produced radicals (see for example equation (4)) or ions are important too. Typical electron densities are in the $10^{17}-10^{18} \mathrm{~m}^{-3}$ range at electron temperatures of 4 $8 \mathrm{eV}$. The operating pressures can be chosen low (in the milli-Torr range) and thus the dissociation and ionization degree approach the percentage range. A self-bias develops close to the substrate which is typically a factor of five times the electron temperature in pure argon plasma and in the range $20-40 \mathrm{~V}$. An additional RF or DC bias (in the case of the deposition of conductive films) can be applied separately when ion energy is necessary for the production of thin amorphous films. It has been demonstrated that the ion energy and ion density can indeed be independently controlled $[19,20]$.

The mentioned high-density remote-type plasmas are now introduced in industry and it has been demonstrated that high-quality thin films can be deposited. Among these are materials such as $\mathrm{CF}_{x}$ polymers [21], a-C:H [15], $\mathrm{a}^{-\mathrm{SiO}_{x}}$ [16] and diamond [18]. It is evident that highdensity plasma sources open a new field of possibilities of different types of materials with better control of the quality than was available with classical RF capacitively coupled plasma sources.

Although not explicitly mentioned, the high-density sources discussed have their disadvantages too. One of these is the fact that the active region is still an integral part of the plasma source which enables the downstream injected precursors or dissociating fragments to re-enter this active region and thus to cause spurious deposition. This in turn influences the lifetime of the source. Furthermore, due to the low pressure required (in the milli-Torr range) and due to this the low flow utilized (typically in the $100 \mathrm{sccm}$ range), the throughput of these plasma sources is still rather low. An alternative approach to overcome this problem is the plasma source based on an expanding thermal plasma. The remainder of this paper will be devoted to this type of plasma source.

\section{Remote plasma deposition by an expanding thermal plasma}

In figure $1 \mathrm{a}$ schematic drawing is given of the plasma used for the fast deposition of a-C:H and a-Si:H. The deposition set-up consists of a cascaded-arc-produced thermal plasma, 


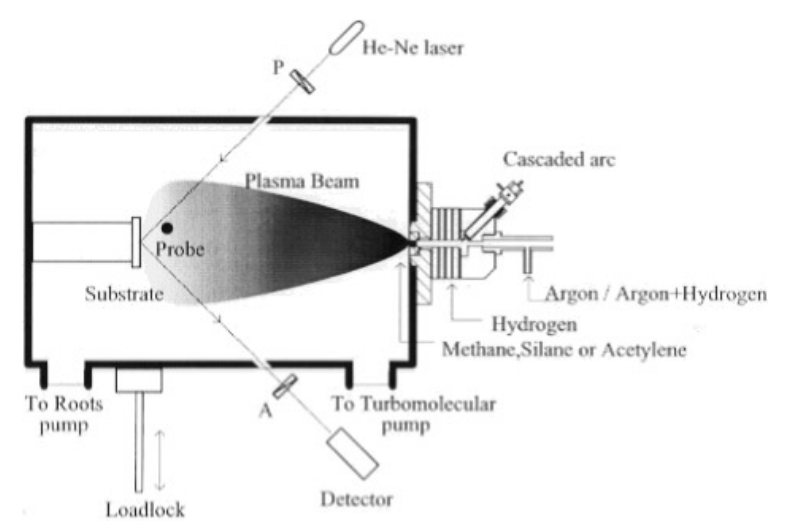

Figure 1. A schematic drawing of the expanding thermal arc plasma.

an expansion vessel and a substrate holder. Through the arc source there is a constant flow, usually of argon or of an argon-hydrogen mixture (typically in the $100 \mathrm{scc} \mathrm{s}^{-1}$ range), at sub-atmospheric pressures, which is ionized to a degree varying from 5 to $25 \%$ depending on the arc conditions. The arc plasma expands into the vessel which is kept at low pressure (typically $25 \mathrm{~Pa}$ ). Downstream precursors for growth such as $\mathrm{SiH}_{4}, \mathrm{C}_{2} \mathrm{H}_{2}$ or $\mathrm{CH}_{4}$ are injected, into the nozzle, into a ring around the plasma beam or directly into the background. The formed plasma mixture flows towards a substrate holder where deposition takes place. The homogeneity of the deposition is within $20 \%$ over an area of $100 \mathrm{~cm}^{2}$. A more extensive description of the set-up is given elsewhere [22-24].

An essential difference between the expanding thermal plasma and other high-density plasma sources or the capacitively coupled plasmas is the way in which the precursors are dissociated. Because the electron temperature is low within the expansion region $[25,26]$, the precursors cannot be dissociated by means of electron impact. Instead they are dissociated by a chain of charge exchange with the $\mathrm{Ar}^{+}$ions produced in the arc, for example for acetylene

$$
\mathrm{Ar}^{+}+\mathrm{C}_{2} \mathrm{H}_{2} \rightarrow \mathrm{Ar}+\mathrm{C}_{2} \mathrm{H}_{2}^{+}
$$

followed by dissociative recombination of the formed molecular ion,

$$
\begin{aligned}
\mathrm{C}_{2} \mathrm{H}_{2}^{+}+\mathrm{e} & \rightarrow \mathrm{CH}+\mathrm{CH} \\
& \rightarrow \mathrm{C}_{2} \mathrm{H}+\mathrm{H}
\end{aligned}
$$

and so on, each with different rates. The formed molecules are electronically and rovibrationally excited and, depending on the amount of ions left, undergo another sequence of charge exchange and dissociative recombination. The first step is the time-limiting step with rates of the order of $10^{-16}-10^{-17} \mathrm{~m}^{3} \mathrm{~s}^{-1}[27,28]$. This manner of dissociation of the injected precursor is very efficient and the material freedom is large: all molecules having an ionization potential lower than that of argon, such as $\mathrm{SiH}_{4}$ and $\mathrm{CH}_{4}$, can be dissociated by reactions analogous to equations (5) and (6). Furthermore, by changing the precursor flow and the arc settings such as power or flow, the dominant radical can be tuned. For example by injecting a little precursor gas into the plasma beam the precursor can be nearly fully dissociated, even up to the atomic components. Note that the sequence of reaction equations (5) and (6) leads to a decrease in the degree of ionization of the plasma as observed by Langmuir probe measurements [29]. For the conditions mentioned the ion density close to the substrate will be of the order of the $10^{17}-10^{18} \mathrm{~m}^{-3}$ at electron temperatures in the range 2000 $3000 \mathrm{~K}$. The self-bias is low, typically $1.5 \mathrm{~V}$ for argon plasmas. The substrate can be biased independently by applying an RF bias. Radical and ion fluxes are respectively in the $10^{21}-10^{22} \mathrm{~m}^{-2} \mathrm{~s}^{-1}$ and $10^{20}-10^{21} \mathrm{~m}^{-2} \mathrm{~s}^{-1}$ range.

Note that the chemical energy is contained in the ions and or radicals (for example atomic hydrogen) created in the cascaded-arc plasma source and that the ions and or radicals emanating from the cascaded arc are used to dissociate and ionize the injected precursors. Due to the large pressure difference between arc and expansion vessel the source is truly geometrically separated. Another important difference with the other high-density plasma discussed is the larger level of flow and power, respectively in the $100 \mathrm{scc} \mathrm{s}^{-1}$ and several kilowatts range. A large flow of chemical active particles is obtained, thereby bringing high deposition rates over large areas $\left(100 \mathrm{~cm}^{2}\right)$ within reach. Using the described source a-C:H and a-Si:H have been deposited with large growth rates (typically $7 \mathrm{~nm} \mathrm{~s}^{-1}$ for a-Si:H and up to $50 \mathrm{~nm} \mathrm{~s}^{-1}$ for a-C:H while maintaining quality).

\section{Deposition of a-Si:H and a-C:H}

One of the main advantages to use plasmas to deposit thin amorphous films is the relatively low substrate temperature which can be used $\left(<400^{\circ} \mathrm{C}\right)$. The reason is that the plasma creates radicals and or ions which have a much higher sticking probability than the injected precursors. The distinction between chemical vapour deposition (CVD) and plasma enhanced CVD is therefore the absence of a high substrate temperature in the latter process. A consequence of this is that the dissociative chemisorption of, for example, $\mathrm{SiH}_{4}$ during a-Si:H deposition can be neglected. Similar arguments hold for $\mathrm{CH}_{4}$ and $\mathrm{C}_{2} \mathrm{H}_{2}$ during a-C:H deposition.

The reactive sticking probability depends on the surface state. In the case of hydrogenated amorphous silicon and carbon deposition the reactive sticking probability depends critically on whether the surface is hydrogenated or not. The hydrogenation of the surface is a result of the balance of the different fluxes arriving at the surface. Another important aspect of the depositing particle is whether the mobility parallel to the surface is large. Of course this is connected to the state in which the precursor for growth is adsorbed, namely whether the precursor is chemisorbed or physisorbed. In the latter case the binding energy is rather low (typically $0.2-0.8 \mathrm{eV}$ ), resulting in relatively large surface mobility already for low substrate temperatures [8]. On the other hand, if the particle is chemisorbed the mobility on the surface is in general low due to the large binding energy (at least over $3 \mathrm{eV}$ for $\mathrm{Si}-\mathrm{H}$ and $\mathrm{C}-\mathrm{H}$ ). 


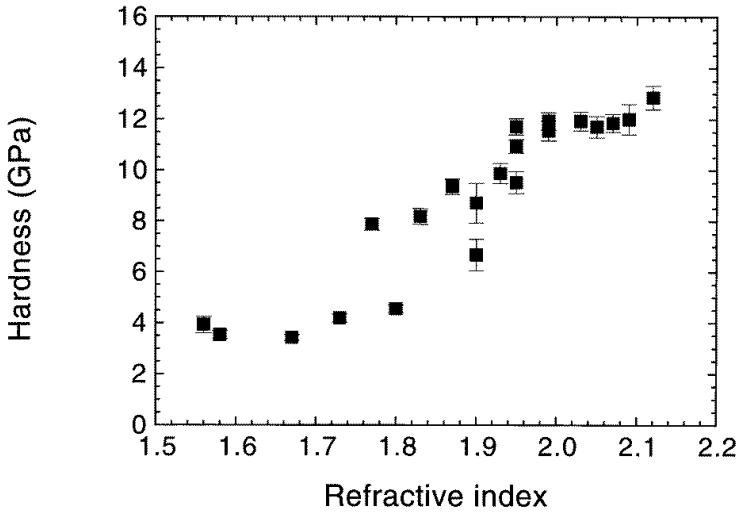

Figure 2. The hardness determined from nano-indention measurements as a function of the refractive index determined from infrared transmission spectrometry. Different $\mathrm{C}_{2} \mathrm{H}_{2}$ flow and arc current settings are used to obtain different refractive indices.

First we will discuss the deposition of a-C:H using an $\mathrm{Ar}-$ $\mathrm{C}_{2} \mathrm{H}_{2}$ plasma, after which we will describe the deposition of a-Si:H using an $\mathrm{Ar}-\mathrm{H}_{2}-\mathrm{SiH}_{4}$ plasma.

\section{1. $\mathrm{a}-\mathrm{C}: \mathrm{H}$}

The settings at which a-C:H films were deposited are given in table 1. The films were analysed using infrared absorption spectrometry to determine the refractive index and the thickness of the films. Also the different $\mathrm{C}-\mathrm{H}$ bonding types can be distinguished in the region around $3000 \mathrm{~cm}^{-1}$ [30]. Furthermore, the hardness was determined using a nano-indenter. By varying the $\mathrm{C}_{2} \mathrm{H}_{2}$ flow and the arc current different films were deposited. In figure 2 the hardness as a function of refractive index in the infrared is given for various arc current and $\mathrm{C}_{2} \mathrm{H}_{2}$ flow settings. It can be seen that the hardness correlates with the refractive index, a result which is in agreement with the results of others [2]. Therefore the refractive index is used as an indication of the hardness. Note that the maximum refractive index is around $14 \mathrm{GPa}$, a value which is approximately $30 \%$ lower than the values obtained using the classical RF capacitively coupled plasma source [2, 12].

In figure 3 the refractive index is given as a function of the $\mathrm{C}_{2} \mathrm{H}_{2}$ flow for different arc currents. It is observed that the refractive index has an optimum depending on the arc current and $\mathrm{C}_{2} \mathrm{H}_{2}$ flow. Since the ion flux increases with increasing arc current, it can be concluded that, at larger $\mathrm{C}_{2} \mathrm{H}_{2}$ flow, more ions are needed to get a higher refractive index (a greater hardness). For example, for a $\mathrm{C}_{2} \mathrm{H}_{2}$ flow of $20 \mathrm{scc} \mathrm{s}^{-1}$ we need an arc current of $75 \mathrm{~A}$ to get the highest refractive index, for $48 \mathrm{~A}$ the optimum is obtained at $10 \mathrm{scc} \mathrm{s}^{-1}$ after which a further increase in the current has little effect on the obtained refractive index and thus hardness. From ion density measurements using Thomson scattering, it can be inferred that the refractive index has an optimum at which the amount of ions emanating from the arc approximately equals the number of injected $\mathrm{C}_{2} \mathrm{H}_{2}$ molecules [25]. This suggests that the injected $\mathrm{C}_{2} \mathrm{H}_{2}$ is near to being fully dissociated in this particular condition. In fact, looking at the optimum refractive index as a function

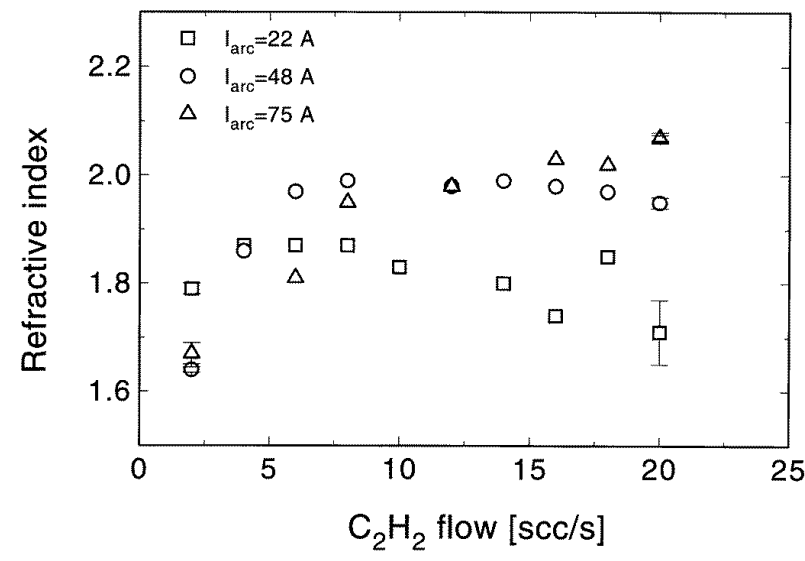

Figure 3. The refractive index determined from infrared transmission spectrometry as a function of the $\mathrm{C}_{2} \mathrm{H}_{2}$ flow for different arc current settings.

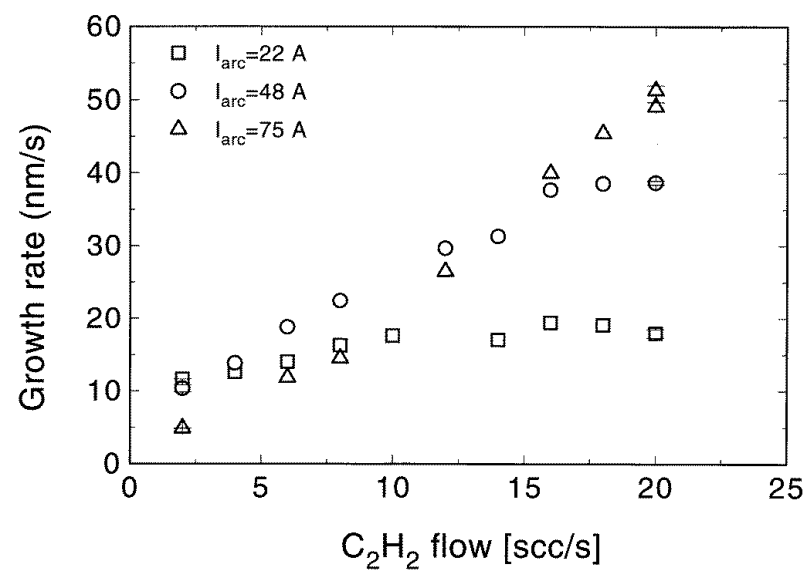

Figure 4. The growth rate determined from infrared transmission spectrometry and the deposition time as a function of the $\mathrm{C}_{2} \mathrm{H}_{2}$ flow for different arc current settings.

of the $\mathrm{C}_{2} \mathrm{H}_{2}$ flow for the different arc currents it can be concluded that, to obtain a high refractive index (a great hardness), one should adjust the $\mathrm{C}_{2} \mathrm{H}_{2}$ flow to match the amount of ions emanating from the arc: much more ions than $\mathrm{C}_{2} \mathrm{H}_{2}$ molecules leads to a richer chemistry, much more $\mathrm{C}_{2} \mathrm{H}_{2}$ than argon ions leads probably to an interaction of the injected $\mathrm{C}_{2} \mathrm{H}_{2}$ left over with the radicals formed in the interactions with the argon ions. In figure 4 the growth rate is given as a function of the $\mathrm{C}_{2} \mathrm{H}_{2}$ flow for the same settings as shown in figure 3 . It can be seen that the growth rate increases with increasing $\mathrm{C}_{2} \mathrm{H}_{2}$ flow. Combining figures 3 and 4 , this means that the quality increases with increasing growth rate. Note that the greatest hardness is obtained at the highest growth rate of approximately $50 \mathrm{~nm} \mathrm{~s}^{-1}$.

The deposition mechanism of a-C:H using the expanding thermal arc method is still uncertain. However, using a simple model with certain straightforward assumptions we can determine the reactive sticking probability of the depositing radical. As mentioned the dissociation of $\mathrm{C}_{2} \mathrm{H}_{2}$ occurs by means of a charge exchange with the abundant ions in the expansion region. The only exothermic reaction which can occur when a $\mathrm{C}_{2} \mathrm{H}_{2}$ radical reacts with an ion is the formation of the 


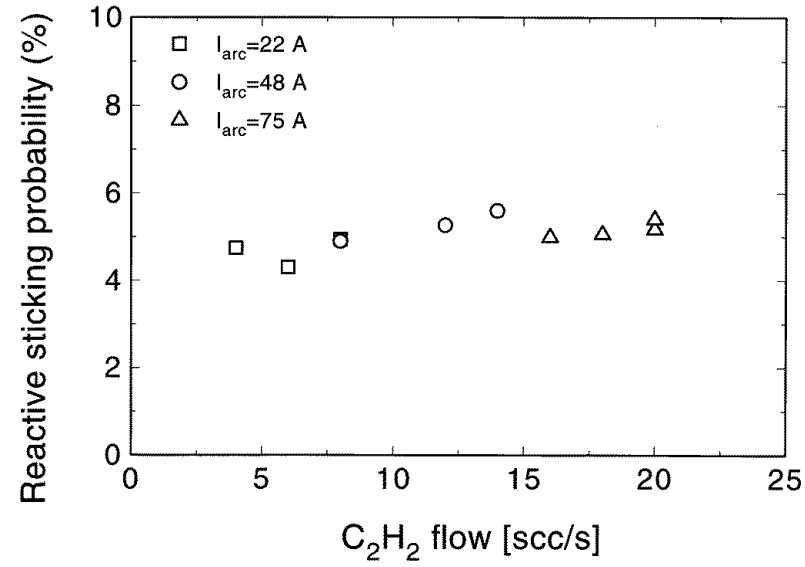

Figure 5. The reactive sticking probability under different plasma conditions.

$\mathrm{C}_{2} \mathrm{H}_{2}^{+}$molecular ion [27]. This ion is lost quickly by dissociative recombination with an electron. The rate for these processes is large, typically $10^{-13} \mathrm{~m}^{3} \mathrm{~s}^{-1}$, probably independently of the products formed in the recombination [31]. The deposition of a-C:H is ruled by a particular radical if a particular channel in this recombination is dominant. Using the available literature two channels are dominant, see equations $(6 a)-(6 b)$, namely the formation of $\mathrm{CH}$ and $\mathrm{C}_{2} \mathrm{H}$ [32]. Preliminary emission spectroscopy results in the case of the expanding thermal arc indicate a dominant generation of the $\mathrm{C}_{2} \mathrm{H}$ radical of more than $90 \%$ [33]. Therefore in the simple model that we are going to discuss we will assume that the $\mathrm{C}_{2} \mathrm{H}$ radical is dominantly formed in the expansion region.

From the results presented in figure 3 we concluded that, under optimum conditions, the $\mathrm{C}_{2} \mathrm{H}_{2}$ flux equals the ion flux. Therefore it seems logical to assume that the $\mathrm{C}_{2} \mathrm{H}$ radical flux equals the initial ion flux. In that case the $\mathrm{C}_{2} \mathrm{H}$ radical flux can be calculated if the ion flux is known. On the other hand, from the deposition rate measured (obtained from the thickness determined from the infrared transmission spectra and the deposition time), the $\mathrm{C}_{2} \mathrm{H}$ flux which actually contributes to growth can be calculated. For this we need the density of the a-C:H deposited. This is done by assuming a density of $1650 \mathrm{~kg} \mathrm{~m}^{-3}$ for a infrared refractive index of 2 , a value confirmed by nuclear analysis measurements. Furthermore, we take the differences due to the refractive indices measured into account by means of a Clausius-Mossoti type of equation. The ratio of the two calculated fluxes gives the reactive sticking probability and is shown in figure 5 for the different arc current and $\mathrm{C}_{2} \mathrm{H}_{2}$ flow settings. In this calculation we only took into account those films with a refractive index larger than 1.9, namely the region in figure 3 within which an optimum refractive index is observed. It can be seen that the reactive sticking probability is constant for the different plasma settings and is approximately $5 \%$, indicating that the deposition for these different conditions is indeed controlled by a similar deposition process. Note that this $5 \%$ sticking probability is based on the assumption that the $\mathrm{C}_{2} \mathrm{H}_{2}$ is nearly fully dissociated. The other extreme case is that the $\mathrm{C}_{2} \mathrm{H}_{2}$ degree of dissociation is only $5 \%$ and the sticking
Table 1. The plasma settings during a-C:H deposition.

\begin{tabular}{ll}
\hline Argon flow & $100 \mathrm{scc} \mathrm{s}^{-1}$ \\
Acetylene flow & $2-20 \mathrm{scc} \mathrm{s}^{-1}$ \\
Arc current & $20-80 \mathrm{~A}$ \\
Arc power & $1-5 \mathrm{~kW}$ \\
Arc pressure & $400-600 \mathrm{kPa}$ \\
Vessel pressure & $25-30 \mathrm{~Pa}$ \\
\hline
\end{tabular}

Table 2. The plasma settings during a-Si:H deposition.

\begin{tabular}{ll}
\hline Argon flow & $30-70 \mathrm{scc} \mathrm{s}^{-1}$ \\
Hydrogen flow & $1-20 \mathrm{scc} \mathrm{s}^{-1}$ \\
Silane flow & $1-20 \mathrm{scc} \mathrm{s}{ }^{-1}$ \\
Arc current & $20-80 \mathrm{~A}$ \\
Arc power & $1-5 \mathrm{~kW}$ \\
Arc pressure & $400-600 \mathrm{kPa}$ \\
Vessel pressure & $25-30 \mathrm{~Pa}$ \\
\hline
\end{tabular}

probability equal to unity. This seems unlikely because we observed that the quality of the deposited $\mathrm{C}_{2} \mathrm{H}_{2}$ attains its maximum under conditions for which the number of argon ions emanating from the arc equalled the amount of injected $\mathrm{C}_{2} \mathrm{H}_{2}$. Furthermore, the refractive index and hardness depend on the $\mathrm{C}_{2} \mathrm{H}_{2}$ flow at constant arc current. This indicates a critical dependence on the radical composition which is only possible when the dissociating capacity of the plasma emanating from the arc is exactly that required to dissociate the amount of $\mathrm{C}_{2} \mathrm{H}_{2}$ injected. Only in this case is the radical composition specific.

We observed that the hardness increased with increasing growth rate. Microscopically this means that the connectivity of the network was improved; that is, either the $\mathrm{sp}^{3} / \mathrm{sp}^{2}$ ratio was increased or the hydrogen content was decreased. Note that the deposition rates are large, more than an order of magnitude larger than deposition rates obtained using other techniques such as the classical RF PECVD. Note, furthermore, that the increase in hardness is not controlled by ion kinetic energy as is usually assumed [34,35]. An important issue is that the growth of a-C:H using the expanding cascaded-arc set-up is fully surface-determined due to the absence of ion bombardment. Support for this is found in recent results of Keudell et al [4], who used in situ ellipsometry to determine the interaction depth as a function of the ion energy. Extrapolation of these measurements to ion energies relevant for the expanding thermal arc plasma means that the interaction depth at $1.5 \mathrm{eV}$ is at most one monolayer thick. Moreover, the ion flux decreases as more $\mathrm{C}_{2} \mathrm{H}_{2}$ is injected, see equations (5) and (6), which means that the growth rate increases with decreasing ion flux. We therefore conclude that the deposition of a-C:H using the expanding thermal arc is ruled by surface processes.

If the assumptions made, namely that $\mathrm{C}_{2} \mathrm{H}$ is the depositing particle, are correct, the observed reactive probability is rather low because it is generally assumed that $\mathrm{C}_{2} \mathrm{H}$ has a sticking probability nearly equal to unity on a non-hydrogenated surface [36]. Hence, we have to conclude that the surface is hydrogenated, leading to 
Table 3. The film properties of the best a-Si:H film deposited.

\begin{tabular}{llll}
\hline Growth rate & $7 \mathrm{~nm} \mathrm{~s}^{-1}$ & $\sigma_{\text {photo }}$ & $2 \times 10^{-6} \Omega^{-1} \mathrm{~cm}^{-1}$ \\
$n_{\mathrm{He}-\mathrm{Ne}}$ & 4.0 & $\sigma_{\text {ph }} / \sigma_{d}$ & $10^{5}$ \\
$n_{I R}$ & 3.3 & $E_{\text {act }}$ & $1 \mathrm{eV}$ \\
{$[\mathrm{H}]$} & $7 \%$ & $\mu \tau_{\text {electron }}$ & $2 \times 10^{-8} \mathrm{~cm}^{2} \mathrm{~V}^{-1}$ \\
{$[\mathrm{SiH}] /\left([\mathrm{SiH}]+\left[\mathrm{SiH}_{2}\right]\right)$} & $0.1-0.2$ & $D O S_{\text {midgap }}$ & $7 \times 10^{15} \mathrm{~cm}^{-3}$ \\
$E_{\text {gap, Tauc }}$ & $1.7 \mathrm{eV}$ & $E_{\text {Urbach }}$ & $50 \mathrm{meV}$ \\
\hline
\end{tabular}

a smaller effective sticking probability (a similar reason would hold for the radical $\mathrm{CH}$ [37]) which depends on the exact surface state. Since the refractive index is almost independent of the substrate temperature in the range $50-150{ }^{\circ} \mathrm{C}$, we assume that the $\mathrm{C}_{2} \mathrm{H}$ radical is directly incorporated when arriving at a dangling bond. On the other hand, when the $\mathrm{C}_{2} \mathrm{H}$ radical arrives at a hydrogenated site it either abstracts a hydrogen and desorbs as $\mathrm{C}_{2} \mathrm{H}_{2}$ or it is reflected. Therefore the effective sticking probability equals the hydrogen surface coverage, which results from the arriving $\mathrm{H}$ and $\mathrm{C}_{2} \mathrm{H}$ fluxes.

\section{2. a-Si:H}

Using the expanding plasma beam set-up a-Si:H films were deposited. The best conditions to deposit a-Si:H investigated so far are given in table 2. The argon plasma in the arc is diluted by hydrogen, leading to predominantly $\mathrm{H}$ and $\mathrm{H}^{+}$emanating from the arc. In the expansion the ion density quickly decreases due to the observed anomalous recombination [38]. Therefore atomic hydrogen is the only active species which is able to dissociate the injected $\mathrm{SiH}_{4}$ downstream. Probably this favours the abstraction reaction of $\mathrm{SiH}_{4}$, equation (4), leading predominantly to the $\mathrm{SiH}_{3}$ radical. Furthermore, the conditions are such that only one abstraction reaction occurs in the gas phase from the point of injection of $\mathrm{SiH}_{4}$ to the substrate. If the arc plasma is not diluted with hydrogen, Ar ions will be the active species and similar reactions of these ions with $\mathrm{SiH}_{4}$ will occur as given in equations (5) and (6). However, because $\mathrm{SiH}_{4}^{+}$is unstable the charge exchange step will lead to $\mathrm{SiH}_{3}^{+}$, which will dissociatively recombine to form $\mathrm{SiH}_{2}$. The films deposited without the dilution of $\mathrm{H}_{2}$ usually have a porous structure, probably as a consequence of the formation of $\mathrm{SiH}_{2}$ [29].

From Langmuir probe measurements it was concluded that the ion density decreased when the growth rate increased [29,39]. Combining this with the fact that the measured self-bias voltages are low, leads us to the conclusion that the growth of a-Si:H in this case is again totally surface process determined. In table 3 the results obtained up to now are shown. The important properties such as the density of states (DOS) at midgap and the photoresponse are within the device quality range needed for photovoltaic applications [1]. It should be noted that we need a relatively high substrate temperature of $320^{\circ} \mathrm{C}$ in comparison with the deposition of a-Si:H using classical $\mathrm{RF}$ plasmas $\left(250^{\circ} \mathrm{C}\right)$. This is consistent with the high deposition rate (see table 3), as was discussed by Matsuda et al [3]. Since the abstraction reaction equation (4) is favoured under the conditions given in table 2, we will assume that the deposition is mainly governed by the $\mathrm{SiH}_{3}$ radical. Using the frequently reported sticking probability of approximately $0.1[3,8,9,13]$, the $\mathrm{SiH}_{3}$ flux $\Phi_{\mathrm{SiH}_{3}}$ towards the substrate can be calculated from the growth rate and density of a-Si:H (about $5 \times 10^{28} \mathrm{~m}^{-3}$ ) to be

$$
\Phi_{\mathrm{SiH}_{3}} \simeq 4 \times 10^{21} \mathrm{~m}^{-2} \mathrm{~s}^{-1} \text {. }
$$

This flux should equal the thermal flux of the $\mathrm{SiH}_{3}$ radical towards the growth surface. Using a temperature of 2000 $3000 \mathrm{~K}$ for the $\mathrm{SiH}_{3}$ radical leads to a $\mathrm{SiH}_{3}$ density of $10^{19} \mathrm{~m}^{-3}$. At the given flow settings and pressure, this would mean that silane is dissociated to a degree of 10 $25 \%$. This degree of dissociation is consistent with the assumption that one abstraction reaction occurs during the transport of the plasma from injection to substrate. Here we have neglected direct incorporation of the arriving radicals, since the sticking probability is 0.1 and we assume that the deposition is determined by the thermal $\mathrm{SiH}_{3}$ flux. If, however, there is a contribution from the $\mathrm{SiH}_{2}$ radical, which has a sticking probability of 0.7 , a lower degree of dissociation would result [13].

The strong temperature-dependence of thermal growth of device quality a-Si:H using the expanding arc technique can be explained as follows [40]. A model, similar to that of Matsuda et al $[3,8,9]$ will be employed here. The surface coverage of the hydrogenated surface is determined by three processes. The first one is the sticking of the $\mathrm{SiH}_{3}$ radical which diffuses on the hydrogenated surface to a non-hydrogenated site with sticking probability $P_{s}$. The second process is the abstraction of a hydrogen atom by a $\mathrm{SiH}_{3}$ radical with probability $P_{a}$. The sticking and abstraction probability are a function of the hydrogen surface coverage $\theta_{H}$ which should be close to unity [6]. It is essential that in these probabilities the processes occurring in the physisorbed state are included. Moreover, since the hydrogen coverage is close to unity $[6,7]$, the growth through the physisorbed state is dominant. The balance for the surface coverage $\theta_{H}$ is given by

$$
\Phi_{S i H_{3}}\left(1-\theta_{H}\right) P_{s}-\Phi_{S i H_{3}} \theta_{H} P_{a}-N \theta_{H}^{2} / \tau_{d e s}=0
$$

with $N$ the total number of growth sites and $\tau_{d e s}$ the time for thermal desorption of $\mathrm{H}_{2}$. Since the growth rate is proportional to the first term it means that, when the growth rate is large, the thermal desorption can be neglected. Since the abstraction probability is lower for higher substrate temperatures this means that the amount of dangling bonds on the surface $\left(1-\theta_{H}\right)$ is lower for larger growth rates. This eventually leads to lower defect densities as the dangling 
bonds on the surface are statistically incorporated into the bulk $[3,8,9]$. So better material is deposited at larger growth rates since thermal desorption, a defect creating mechanism, can be neglected. Increasing the substrate temperature together with an increasing $\mathrm{SiH}_{3}$ flux (thus increasing the growth rate) increases the quality of the a-Si:H deposited.

\section{Conclusions}

The different plasma deposition techniques were discussed. It has been shown that, in terms of specific plasma parameters, the expanding thermal arc is similar to other high-density sources. The throughput, however, in terms of deposition rate is larger for the expanding thermal arc technique. The deposition of a-Si:H and a-C:H using the expanding thermal technique has been discussed. Highquality a-Si:H and a-C:H were deposited at relatively large rates, $7 \mathrm{~nm} \mathrm{~s}^{-1}$ for a-Si:H and $50 \mathrm{~nm} \mathrm{~s}^{-1}$ for a-C:H. Furthermore, it was argued that an increasing growth rate does not necessarily lead to lower quality.

\section{Acknowledgments}

This work has been supported in part by the Foundation for Fundamental Research on Matter (FOM), the Netherlands Technology Foundation (STW), the Netherlands Organization for Energy and Environment (NOVEM) and the Royal Netherlands Academy of Arts and Sciences. The skilful technical assistance of M J F van de Sande, A B M Hüsken and $\mathrm{H} \mathrm{M}$ de Jong is greatly acknowledged. The hardness measurements were performed by VITO and those of the DOS at midgap by the Delft University of Technology

\section{References}

[1] Luft W and Simon Tsuo Y 1993 Hydrogenated Amorphous Silicon Alloy Deposition Processes (New York: Marcel Dekker)

[2] Clausing R E, Horton L L, Angus J C and Koidl P (eds) 1991 Diamond and Diamond-like Films and Coatings (New York: Plenum)

[3] Ganguly G and Matsuda A 1993 Phys. Rev. B 473661

[4] von Keudell A and Jacob W 1995 Appl. Phys. Lett. 661323

[5] Li Y M, An I, Nguyen H V, Wronski C R and Collins R W 1992 Phys. Rev. Lett. 682815

[6] Blayo N and Drevillon B 1990 Appl. Phys. Lett. 57786

[7] Toyoshima Y, Arai K, Matsuda A and Tanaka K 1990 Appl. Phys. Lett. 571028

[8] Guizot J L, Nomoto K and Matsuda A 1991 Surf. Sci. 244 22
[9] Matsuda A, Nomoto K, Takeuchi Y, Suzuki A, Yuuki A and Perrin J 1990 Surf. Sci. 22750

[10] Kushner M J 1988 J. Appl. Phys. 632532

[11] Möller W 1993 Appl. Phys. A 56527

[12] Dekempeneer E H A, Smeets J, Meneve J, Eersels L and Jacobs R 1994 Thin Solid Films 241269

[13] Kea Nune P, Perrin J, Guillon J and Jolly J 1995 Plasma Sources Sci. Technol. 4250

[14] 1994 Plasma Sources Sci. Technol. 3 239-452

[15] von Keudell A, Möller W and Hytry R 1993 Appl. Phys. Lett. 62937

[16] Perry A J, Vender D and Boswell R W 1991 J. Vac. Sci. Technol. B 9310

[17] Hopwood J, Guarnieri C R, Whitehair S J and Cuomo J J 1993 J. Vac. Sci. Technol. A 11147

[18] St-Onge L and Moisan M 1994 Plasma Chem. Plasma Process. 1487

[19] Aydil E, Gregus J A and Gottscho R A 1993 Rev. Sci. Instrum. 643572

[20] Kortshagen U 1995 Plasma Sources Sci. Technol. 4172

[21] Takahasi K, Hori M and Goto T 1993 Japan. J. Appl. Phys. $32 \mathrm{~L} 1088$

[22] Buuron A J M, van de Sanden M C M, van Ooij W J, Driessens R M A and Schram D C 1995 J. Appl. Phys. 78528

[23] de Graaf M J, Severens R J, Dahiya R P, van de Sanden M C M and Schram D C 1993 Phys. Rev. 482098

[24] Severens R J, Brussaard G J H, van de Sanden M C M and Schram D C 1995 Appl. Phys. Lett. 67491

[25] van de Sanden M C M, de Regt J M and Schram D C 1993 Phys. Rev. E. Sci. Instrum. 472792

[26] Meulenbroeks R F G, van Beek A J, van Helvoort A J G, van de Sanden M C M and Schram D C 1994 Phys. Rev. E. Sci. Instrum. 494397

[27] Maier W B 1965 J. Chem. Phys. 421790

[28] Bowers M and Elleman D 1972 Chem. Phys. Lett. 16486

[29] Meeusen G J, Dahiya R P, van de Sanden M C M, Dinescu G, Zhou Qing, Meulenbroeks R F G and Schram D C 1994 Plasma Sources Sci. Technol. 3521

[30] Dischler B, Bubenzer A and Koidl P 1983 Solid State Commun. 48105

[31] Mul P M and McGowan J W 1980 Astrophys. J. 237749

[32] Millar T J 1988 Astron. Astrophys. 194250

[33] van der Zande M J 1995 Internal report, Eindhoven University of Technology

[34] Robertson J 1993 Diamond Relat. Mater. 2984

[35] Lifshitz Y, Kasi S R and Rabalais J W 1989 Phys. Rev. Lett. 621290

[36] von Keudell 1995 Personal communication

[37] Gogolides E, Mary D, Rhallabi A and Turban G 1995 Japan. J. Appl. Phys. 34261

[38] Severens R J, Brussaard G J H, van de Sanden M C M and Schram D C 1995 Mat. Res. Soc. Symp. Proc. 37732

[39] van de Sanden M C M, Severens R J, Meulenbroeks R F G, de Graaf M J, Qing Z, Otorbaev D K, Engekn R, Gielen J W A M, van der Mullen J A M and Schram D C 1995 Surf. Coat. Technol. 74-75 1

[40] van de Sanden M C M, Severens R J and Schram D C 1996 to be published 